\title{
The Use of Process Monitoring Data for Nuclear Material Accounting
}

\section{Summary Report}

Prepared by R. J. Brouns, B. W. Smith, D. W. Brite, C. O. Harvey

Pacific Northwest Laboratory

Prepared for

U.S. Nuclear Regulatory

Commission 


\section{NOTICE}

This report was prepared as an account of work sponsored by an agency of the United States Government. Neither the United States Government nor any agency thereof, or any of their employees, makes any warranty, expressed or implied, or assumes any legal liability or responsibility for any third party's use, or the results of such use, of any information, apparatus product or process disclosed in this report, or represents that its use by such third party would not infringe privately owned rights.

\section{Available from \\ GPO Sales Program}

Division of Technical Information and Document Control U.S. Nuclear Regulatory Commission Washington, D.C. 20555

and

National Technical Information Service

Springfield, Virginia 22161 
NUREG/CR-1670

PNL-3396

Vol. 1

\section{The Use of Process Monitoring Data for Nuclear Material Accounting}

Summary Report

Manuscript Completeted: August 1980

Date Published: October 1980

Prepared by

R. B. Grours, B. W. Smath, D. W. Brite, C. O. Harvey

Pacific, Northwest Laboratory

Fichland, WA 99352

Prepared for

Office of Nuclear Material Safety and Safeguards

U.S. Nuclear Regulatory Commission

Washington, D.C. 20555

NRC FIN No. B2213 



\section{ABSTRACT}

A study was conducted for the Nuclear Regulatory Commission (NRC) as part of a continuing program to estimate the effectiveness of using process monitoring data to enhance strategic special nuclear material (SSNM) accounting in nuclear facilities. Two licensed fuel fabrication facilities with internal scrap recovery processes were examined. The loss detection sensitivity, timeliness, and localization capabilities of the process monitoring technique were evaluated for single and multiple (trickle) losses. The impact of records manipulation, mass and isotopic substitution, and collusion between insiders as methods for concealing diversion were also studied. 



\section{SIMMARY}

This report describes study of the possible application of the process monituring technlque to two licensed fuel fabrication facllities. For each facility the safeguards effectiveness of an alternative material accounting system using portions of the facility's process mon ltoring data was evaluated and compared with the capabilty of the current material accounting system. The results of the study were sinilar to those of previous investigations by Milas, Glancy and Donelson $(1,2)$ which showed that substantial inprovenent of SNM control can be achleved in a nuclear manufacturing facility by using process monitoring data, However, the extent of applicability and effectiveness would be dependent on the spe ific characteristics of the fac 11 tity.

The estimated anmul incrementa? cost of the altermative systent is a modest staff effort equivaient to the addition of one to 1.5 professional personnel pus a computerized, near real time data handing system. The principat results for the loss detection capability are presented in charts and tables that show the timeliness, senstivity, and loclization to spec if ic process steps and target materia1s. With the current material control and accounting system, the estimated average time from diversion to the detection of the loss wuld be 30 to 35 days for most of the target materlals in the process. (a) some target matertals are checked nore frequent $y$ bec ause they are subject to item control and identification procedures for either accounting or prodution control purposes. For the proposed systen utilizing process moni. toring information, the estifated timeliness for diversion detection ranged from a few hours to a few days rather than 30 to 35 days and the loss detection sensitivities for most target materials are estimated to be a small fration of that of the current material accounting system. These inprovements occur mainly becase there are few process steps between successtve measurements or other material checks. In addition to enhanced timeliness and sensitivity, loss alartns would generally loc alize the trouble point to a small part of the process area and to very fex target materials.

(a) The maximum the is 70 days, based on a requirement for a physical invencory each 60 days and assuming ten days for data evaluation. 
When substitution of other material for diverted SSMM is considered, the timeliness of the process monitoring technique was increased by a few days for many target materials because SSMM assay or isotopic analysis data are required to detect the substitution. However, the detection sensitivities were usually not reduced appreciably.

A multiple diversion strategy could result in an appreciable cumlative SSNM loss over a period of time at a small risk of detection of each single diversion. However, the process monitoring technique facilitates monitoring for a cumulative loss by sequential analyses of mass or material balances because many such balances are obtained in each control unit in the time interval of one conventional material balance period. Therefore, detection of the cumulative loss would be more timely than achieved by the current system. The estinated probabillty of detecting multiple losses before the cumulative sum equals the detection capability limits (time and sensitivity) of the current accounting system was found to be of the order of 90 percent for one-half the target materials in the first plant (HEU) and for three-quarters of the target materials in the second plant (Pu-U mixed oxide).

Data manipulation (falsification) would further delay detection in many cases but with small effects on sensitivity. Some falsification scenarios could prevent detection of diversion in certain process steps if record audits and internal controls were not thorough. In many target materia? locations the collusion of two or more plant personnel would be required to successfully falsify data whout prompt detection. 


\section{CONTENTS}

\begin{tabular}{|c|c|c|c|c|c|c|c|c|c|c|c|c|c|c|}
\hline ABST & $A C T$ & . & . & . & . & - & * & • & • & . & . & . & . & jii \\
\hline SUMM & an & . & . & . & * & . & • & . & + & . & - & " & . & $v$ \\
\hline 1.0 & INTE & 20DUCTION & - & * & • & * & 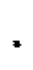 & " & " & . & • & . & * & I \\
\hline 2.0 & MET & Honology & . & , & . & . & * & * & - & • & • & . & . & 3 \\
\hline 3.0 & EVAL & UATION RE & SULS & 5 & • & + & $\bullet$ & $*$ & ' & • & • & • & . & 11 \\
\hline 4.0 & INVE & EST IGATION & OF A & ALARMS & • & . & • & . & • & * & , & " & * & 19 \\
\hline .0 & cont & UUSIONS & . & . & . & * & • & 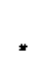 & * & " & * & ' & * & 21 \\
\hline$R E F$ & SENC & $\$$ & . & . & • & . & • & * & * & t & • & " & . & 23 \\
\hline
\end{tabular}




\section{FIGURES}

1 Example Control Unit A . . . . . . . . . . 5

2 Example Control Unit B; Uranium Extraction in a Serap

Recovery Process . . . . . . . . . . . . 7

3 Detection Sensitivity versus Target Material Attractiveness; HEV Plant, . . . . , . , * 11

4 Detection Sensitivity versus Timeliness: HEU plant , . . 12

5 Detection Sensitivity for Diversion with Mas5 Substitution versus Target Material Attractiveness; HEЏ Plant. . . . 13

6 Detection Sensitivity versus Target Material Attractiveness; Mox plant . . . . . . . . * . 15

7 Detection Sensitivity versus Timeliness; MDX Plant . . . . 15

8 Jetection Sensitivity for Diversion with Mass Substitution versus Target Materlal Attractiveness . . . . . . 16

\section{TABLES}

1 Characteristics of the Two Nuclear Fuel Fabrication Plants . . 4

2 Localization Effectiveness of the Process Montonting Technique 


\subsection{INTROOUCTION}

The Nuclear Regulatory Cormission is considering a revision of current regulations that would incorporate existing process monitoring practices into a formal regulatory requirement for control of strategic special nuclear material (SSM) in nuclear processing plants. (3) Previous evaluations of the potential effectiveness of using process monitoring data were conducted jointly by Mound Laboratories and Science Applications, Ine. $(1,2)$ In this study the application of the process monitoring technique at two additional licensed facilities was evaluated to help reduce uncertainties about the general application of the technique to all types of faclities and to estimate the effectiveness for detection of multiple (or trickle) losses. Because this study uses process monitoring data that are currently recorded, the effectiveness of process monitoring determined by this study in aiding the safeguarding of SNM is also an approxination of the current benefits. To achieve the full benefits, performance should be quantified and formal procedures that would insure consistent usage must be established. However, consideration should be given in the formalization to the impact of increased alarms because of data errors and the resulting demands for clerical accuracy, both of which are due to a significant increase in the quantity of data in the SNM accountability system. 



\subsection{METHODOLOGY}

Process monitoring data refer to production control, process control, and quality control data. Examples of process control data are flow rate, pH, and specific gravity, and examples of quality control data are chemical and MDA measurements used to insure product quality. Production contrn? data, which consist primarily of results derived from bulk measurements, such as process yields and in-process inventories, were most useful for monitoring fuel fabrication, while process control data were most useful in scrap recovery operations. quality control data were most useful for detecting diversion concealed by a mass or isotopic substitution.

A material accounting system using portions of the factlity's process monitoring data presently taken and recorded was developed and, then evaluated for each facility. To develop the system design, the falsication and scrap recovery processes were described as a series of unit operations with an overTay of production, process, quality control, and nuclear materyal accounting measurement points. All possible target materials for diversion were identified in each unit operation. Finally, the information obtained at each measurement point was applied as a loss monitor over the applicable unit operations and target materials. Most loss monitoring techniques were process yields and mass balances based on net weight data or combined net weight and assay data. Efforts were made to monitor losses over small segments of the process. A summary of the characteristics of the two facilities as they were broken down into unit operations is presented in Table 1.

The material accounting system was evaluated by calculating the effectiveness of using process monitoring to detect loss under various diversion modes. The effectiveness in detecting each diversion was measured by the detection tineliness, mass sensitivity, and degree of localization obtained from the process monitoring and accountability measurements at each process step. This was generaliy achieved by: 1) calculating the average time lapse from the postulated loss to the time when all measurements required to close the balance had been performed and recorded, 2) calculating the variance of the balance, and 3) determining the number of target materials that would have to 
TABLE 1. Characteristics of the Two Nuc lear Fuel Fabrication Plants

\begin{tabular}{|c|c|c|}
\hline & $\begin{array}{l}\text { First plant } \\
\text { High-Enriched } \\
\text { Uranium } \\
\end{array}$ & $\begin{array}{l}\text { Second Plant } \\
\text { Plutonium-Uranium } \\
\text { Mixed Oxide }\end{array}$ \\
\hline \multicolumn{3}{|l|}{ Type of Process: } \\
\hline Conversion & $\mathrm{No}$ & Yes \\
\hline Fabrication & Yes & Yes \\
\hline Scrap Recovery & Yes & Yes \\
\hline \multicolumn{3}{|l|}{$\begin{array}{c}\text { Number of Un it Operations in } \\
\text { Bulk Material Processing: }\end{array}$} \\
\hline Fuel Fabrication & 14 & 33 \\
\hline $\begin{array}{l}\text { Scrap Recovery (ine ludes } \\
\text { conversion in the Mox plant) }\end{array}$ & 24 & 16 \\
\hline \multicolumn{3}{|l|}{ Number of Target Materials: } \\
\hline $\begin{array}{l}\text { Fuel Fabrication } \\
\text { scrap Recovery (includes } \\
\text { conversion in the Mox plant) }\end{array}$ & $\begin{array}{l}20 \\
39\end{array}$ & $\begin{array}{l}49 \\
24\end{array}$ \\
\hline \multicolumn{3}{|l|}{$\begin{array}{l}\text { Number of Target Materials } \\
\text { Monitored by the Process } \\
\text { Mont toring Technique: }\end{array}$} \\
\hline $\begin{array}{l}\text { Fuel Fabrication } \\
\text { Sorap Recovery }\end{array}$ & $\begin{array}{l}20 \\
30\end{array}$ & $\begin{array}{l}45 \\
16\end{array}$ \\
\hline
\end{tabular}

be investigated if the balance closed outside the control limits. The statistical distribution of the variance was assumed to be normal and the alarm limits for the balance were set at a level to minimize false alarms. Calculation of each variance included consideration of measurement errors, estimated process variance, estimated holdup variability, and variability of the scrap and waste generation rates. The sensitivity was then defined as an amount of SSNM loss that would have a $95 \%$ probablity of causing an alarn.

An example of a loss detection unit ("control unit") is given in Figure 2 . This control unit comprises one typical unit operation, blending sublots of plutonium-uranium oxides. The feed materials, $w_{2}$ and $P_{u 0_{2}}$, have known chemical compositions based on previous analyses and only net weighings are 


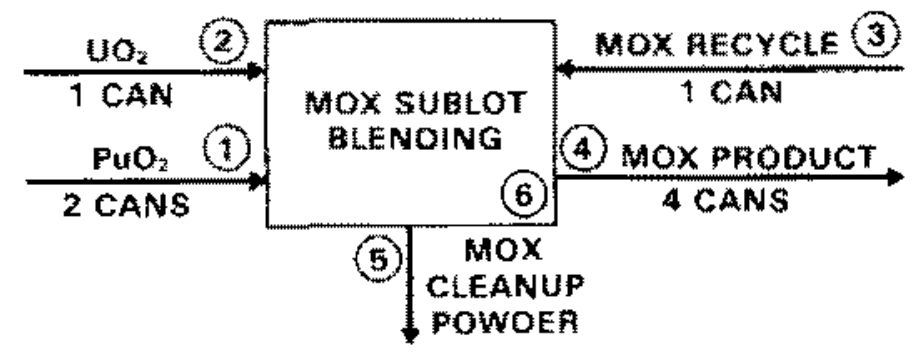

\begin{tabular}{|c|c|}
\hline $\begin{array}{l}\text { MEASUREMENT } \\
\text { POINT } \\
\end{array}$ & $\begin{array}{l}\text { OATA } \\
\text { COLLETEO }\end{array}$ \\
\hline 1 & NW OF $\mathrm{PuO}_{2}$ IN EACH CAN INW! \\
\hline 2 & $\mathrm{NW}$ of $\mathrm{NO}_{2}\left\{\mathrm{NW}_{2}\right\}$ \\
\hline 3 & $\begin{array}{l}\text { NW OF MOX RECYCLED FROM PAEVIOUS } \\
\text { LOTS }\left(N W_{3}\right)\end{array}$ \\
\hline 4 & NW OF MOX IN EACH CAN [NWA] \\
\hline 5 & $\begin{array}{l}\text { NW OF MOX CLEANUP POWOEA COLLECTED } \\
\text { AFTEA TWO SUALOTS INW }{ }_{5} \text { I }\end{array}$ \\
\hline 6 & $\begin{array}{l}\text { ESTMATED AMOUNT OF HOLOUP } \\
\text { OF MOX AND PUD IN THE BLENOING } \\
\text { SYSTEM AND GLOVED EOX }\end{array}$ \\
\hline
\end{tabular}

FIGURE 1. Example Control Unit A. $\mathrm{PuO}_{2}-40_{2}$ Mixed oxide (MOX) Blending

needed to prepare the MOX mixture. Five measurement points for weighings and an estimate of the holdup in the gloved box and equilpment after cleanup are utilized, Cleanup consists of removing visible holdup and spilled powder in the equipment (without disassembly) and on the floor of the gloved box. It is done af ter every Mox lot.

The control unit is monitored for each complete lot of MOX powder, which consists of two sublots. The loss monitoring equation is:

$$
\sum_{i=1}^{4} N W_{1 i}+\sum^{2} N W_{2 i}+\sum^{2} N W_{3 \uparrow}-\sum^{8} N w_{41}-N W_{5}-\varepsilon\left(d W_{6}\right)=\Delta
$$

where $\mathrm{E}\left(\mathrm{dNW_{b }}\right)$ is the estimated change in the holdup and $\Delta$ is the mass balance difference. 
The detection sensitivity is based on an estimate of the standard deviation of the the mass balance, $s_{\Delta}$, and the loss alarm would be set at a multiple of $s_{\Delta}$, such as $2 s_{\Delta}$. The $s_{\Delta}^{2}$ is estimated as follows:

$$
\begin{aligned}
& \quad 4 s_{1}^{2}+2 s_{2}^{2}+2 s_{3}^{2}+8 s_{4}^{2}+s_{5}^{2}+s_{E}^{2}+\left(\sum^{2} N w_{3 i}\right)^{2} \frac{s_{f}^{2}}{f^{2}}+4^{2} s_{1 c}^{2}+2 s_{2 c}^{2} \\
& +2^{2} s_{3 c}^{2}+9^{2} s_{4 c}^{2}=s_{\Delta}^{2}
\end{aligned}
$$

where $s_{1}, s_{2} \ldots s_{5}$ are the standard deviations of net weighings at measurement points 1 through $5, S_{E}$ is the standard deviation of the estimated change in the in-process holdup, $s_{f}$ is the between-lots standard deviation of the plutonium factor, $f$, in $M 0 x$, and $s_{1 c}, s_{2 c}, \ldots s_{4 c}$ are the calibration standard deviations of the weighing systems used (note that $\mathrm{NW}_{4}$ and $\mathrm{NW}_{5}$ are on the same scale). All values of $s$ are expressed in absolute units, such as grams of MoX.

The term for the plutonium factor for the MOX recycle is included because that material is recovered from previous MOX lots and the factor may differ from that of the other material added to and removed from the blending operation. The effect of this difference on the factors for the product, cleanup powder, and holdup is assumed to be small enough to be ignored. It is also assumed that the measurements involved in the control unit are independent and possible correlations between them are ignored.

Other Toss monitoring units were evaluated in a similar manner. Figure 2 shows a typical control unit in an enriched uranium scrap recovery process. The unit operation consists of a typical solvent extraction and interstage concentration cycle. The process is semicontinuous with evaporation by batches and continuous, uniform flow through the extraction columns. The boundaries of the control unit were chosen at measurement points that permit completion of uranium balances over short time intervals. Because the process is shut down for one shift each day, the time interval chosen for a control unit balance is one day of two shifts. A uranium balance is based on recorded flow and uranium concentration measurements made hourly at each measurement point. The 


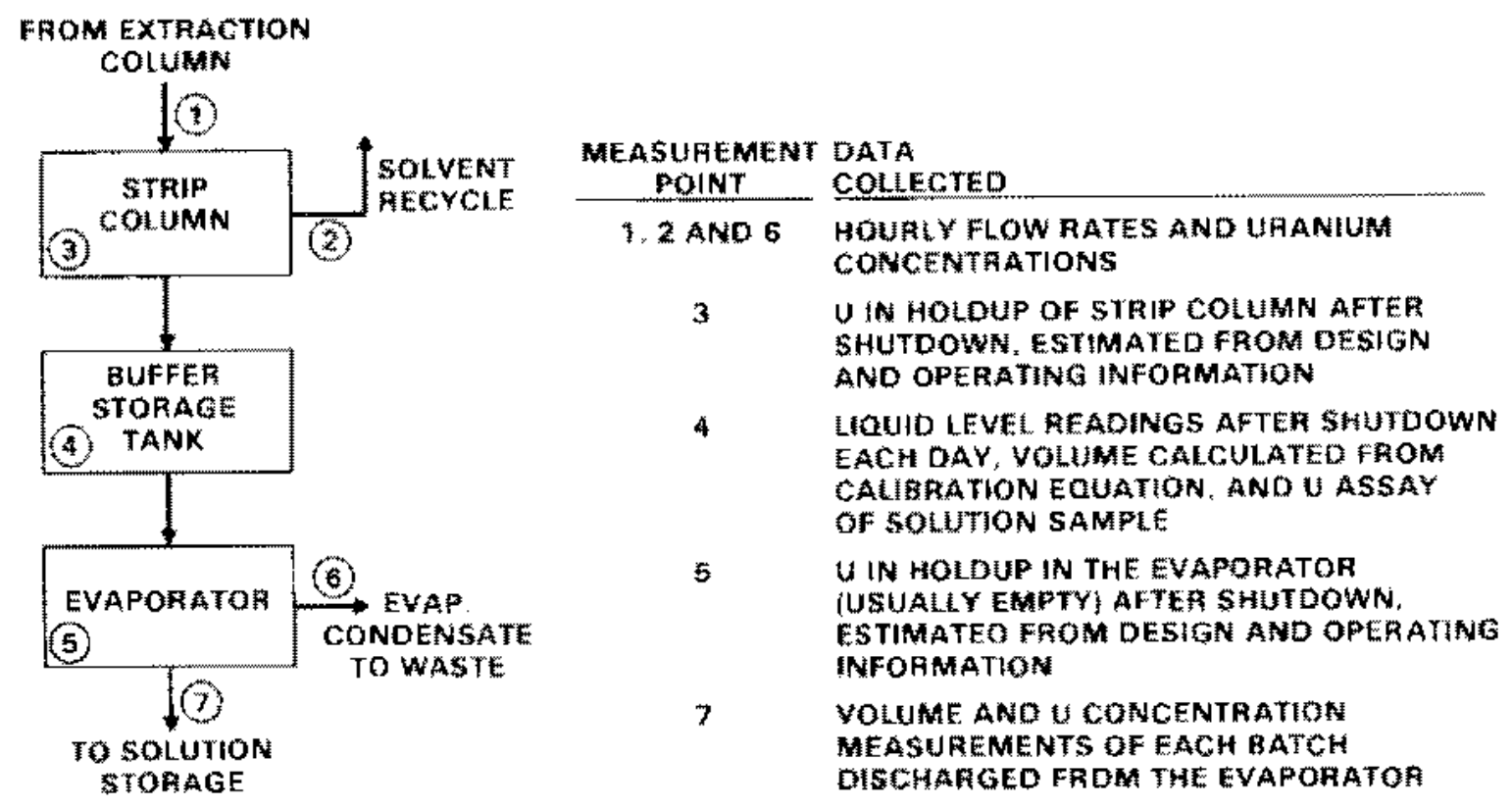

FIGURE 2. Example B, Uranium Extraction in a Scrap Recovery Process

standard deviation of $\Delta$ and the loss alarm level are estimated in a manner similar to that of Example Ax The material balance equation for this contro? un it is:

$$
\begin{aligned}
& \quad \sum u_{1 i} F_{1 i}^{t} t_{1 i}-\sum u_{2 i} F_{2 i} t_{2 i}-\sum u_{6 i} F_{6 i} t_{6 i}-\sum v_{7 i} u_{7 i}-E\left(d U_{3}\right)-E\left(d U_{5}\right) \\
& +\left(v_{4} u_{4}\right)_{b}-\left(v_{4} u_{4}\right)_{e}=\Delta
\end{aligned}
$$

where $U_{1}, U_{z}, \ldots$ = the hourly uranium concentration measurements at points $1,2, \ldots$ respectively. (They were 235 u concentration measurements by NDA)

$F_{1}, F_{2}, \ldots=$ the hourly flow rate measurements at points $1,2, \ldots$ respectively.

$t_{1}, t_{2}, \ldots=$ the time intervals of flow corresponding to $F_{1}$, $F_{2}$, ... respectively.

$v_{7} \quad=$ the volume of a batch discharged from the evaporator. 
$E\left(d_{3}\right)$ and = the estimated differences in the quantities of uranium $\mathrm{E}\left(\mathrm{dU}_{5}\right) \quad$ holdup in the strip column and evaporator at the beginning and end of the day's run.

$\left(U_{4} V_{4}\right)_{b}$ and $=$ the inventories of Tank 4 at the beginning and end of $\left(U_{4} V_{4}\right)_{e} \quad$ the day's run.

One of the diversion scenarios considered was substitution of other material for plutonium or high enriched uranium. In that case, simple mass balance monitoring, as shown in example $A$, would not detect the diversion. However, where assays are performed, as in example B, substitution would not mask the diversion and the detection capability would not be affected. Since the uranium assays in this case are ${ }^{235} U$ determinations (by NDA), isotopic substitution would also be detected. In cases analogous to example A, other, over lapping control units based on monitoring plutonium assay data were used to detect diversion with mass substitution. The detection sensitivities in those cases were estimated by evaluating the variance of the ratio of the input and output assays. The input assay values could be either previous feed assays, nominal values or historical lot average values.

Multiple losses that occur over more than one loss detection interval, often called trickle losses, would usually be detectable using the process monitoring data before the cumulative loss reaches the level of detectability of the current material accounting system. To detect a trick le loss when the rate of loss is too small to be detected in a single intervat, a study should be made of sequential data utilizing loss rate indicators, such as cumulative sums or Kalman filters. (4) Although sufficient information on the statistical characteristics of the loss indicators based on process monitoring data was not available in this study to perform statistical evaluations of sequential data, a cursory analysis of the trickle loss detection capability was performed for each target material. To perform this analysis, the variances of the cumulative loss indicators were assumed to be affected predominantly by the random measurement and process errors. Two cases were chosen as examples to demonstrate the effectiveness of detecting a trickle loss: one in which the 
cumulative loss would equal the high probability detection capability of the current material balance accounting system, 1. e., approximately twice the fac llity Limit of Error of Inventory Difference (LED), and the other in which the cumulative diversion would equal five formia kilograms (FKg) in two months. To determine if there is a high probablity of an alarm from a colckle loss within a two-month period, two tests were performed. The first test calculated the time period until there was a high probabllity of an alarm for at. least one SSMM loss in the series. The second test was based on estimates of the control limats for the cumulative surit of the losses assuning that all process variance is random. If either of the tests indicated that the trickle loss would be detected within two months, the result was classiffed as possible, and if both tests indicated that the trickle loss would be detected, the result was classifled as capable of detecting the trickle loss. 



\subsection{EVALUATION RESULTS}

Examples of the evaluation results for the process monitoring technique are shown in the following figures. Figure 3 shows the sensitivity of loss detection for a simple loss as a function of the target material attractiveness $^{(a)}$ for the HEU facility. The number beside each point indicates the

\section{SENSITIVITY FOR NO SUBSTITUTION CASE}

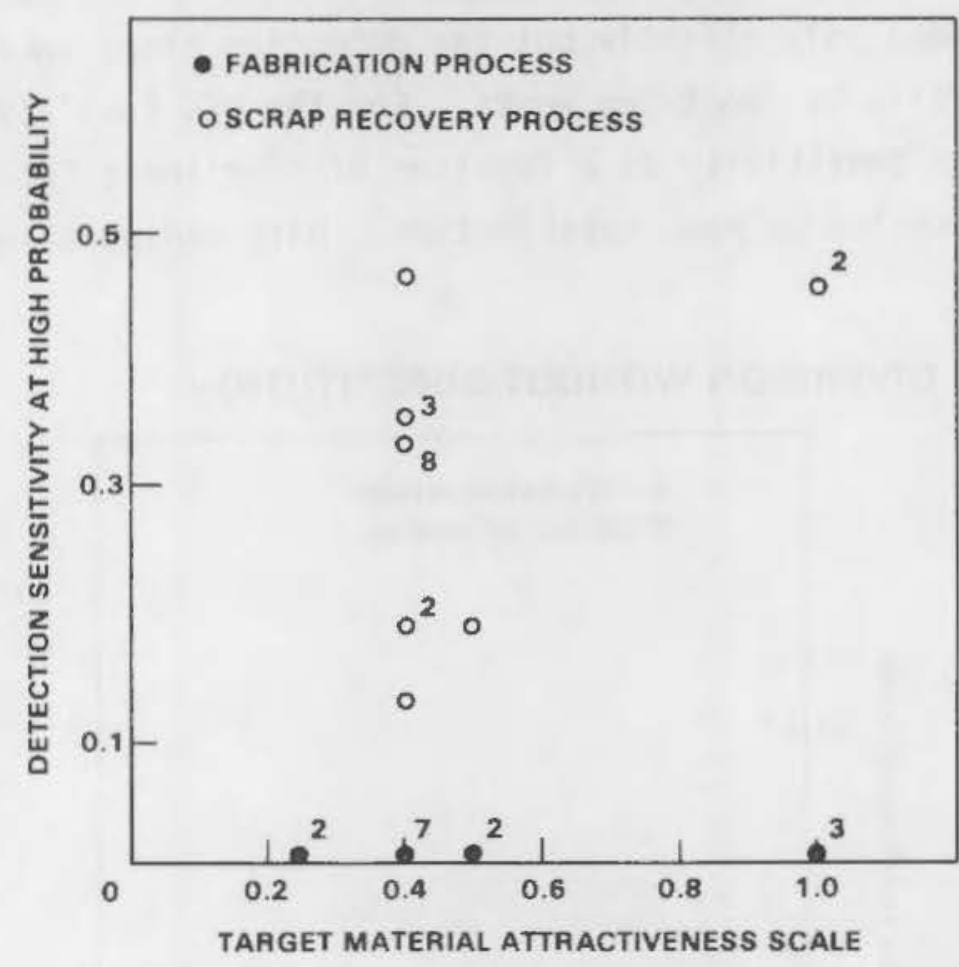

FIGURE 3. Detection Sensitivity versus Target Material Attractiveness; HEU Plant. (Attractiveness values $<0.25$ omitted; sensitivity expressed as a fraction of the facility LEID)

(a) The attractiveness of the target material to a potential adversary is used to interpret the evaluation results. The numeric attractiveness values were based on three characteristics: 1) location, including accessibility to the target material, 2) form, which includes type, purity, and fissile fraction of the material, and 3) mobility, which factors in size, weight, containment, transportability, and ease of concealment. The overall numeric attractiveness value is the simple product of the three values. 
number of target materials that have those characteristics. The sensitivity for each target material is shown as a fraction of the sensitivity for the current SNM accounting system based on LEID.

Figure 4 shows the detection sensitivities for the HEU facility as a function of the timeliness of detection. Average delays of 20 days occur for several target materials in fabrication because a holding period is required to await release by quality control before further processing.

For diversion concealed by substitution of other material, the sensitivities changed only slightly but the detection times increased appreciably, generally by about two weeks. For the HEU facility, Figure 5 shows the detection sensitivity as a function of timeliness for detection of diversion when concealed by mass substitution. Data manipulation would

\section{DIVERSION WITHOUT SUBSTITUTION}

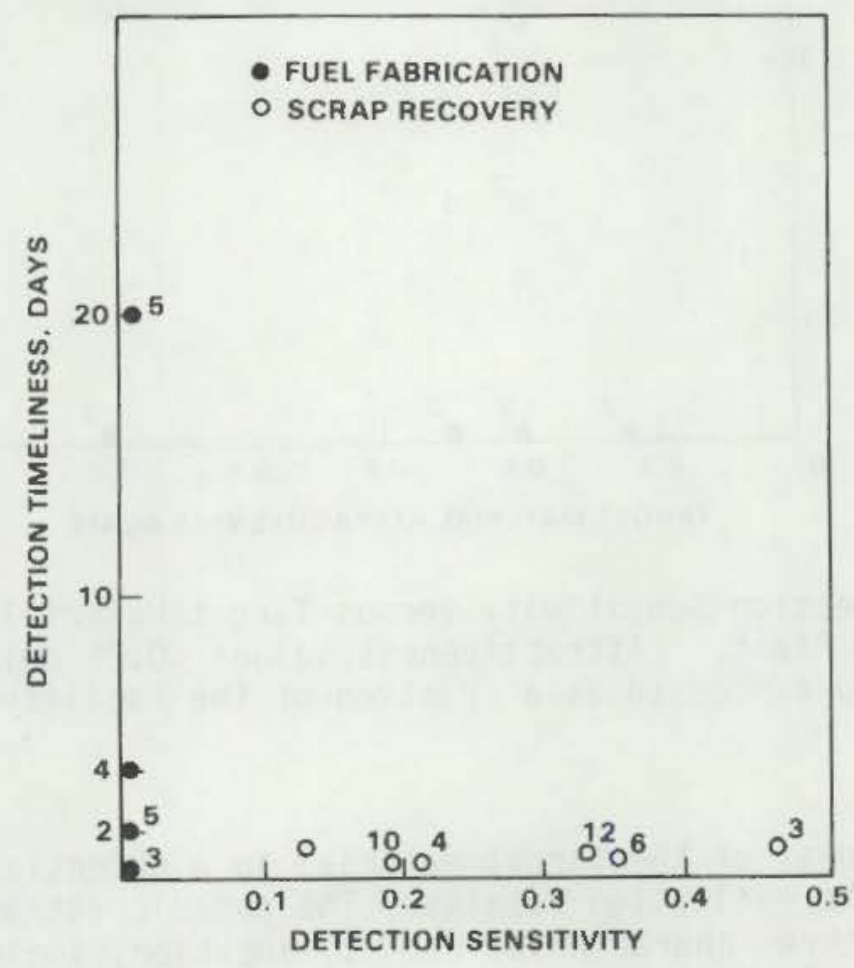

FIGURE 4. Detection Sensitivity versus Timeliness; HEU Plant. (Sensitivity expressed as a fraction of the facility LEID) 


\section{SENSITIVITY FOR MASS SUBSTITUTION CASE}

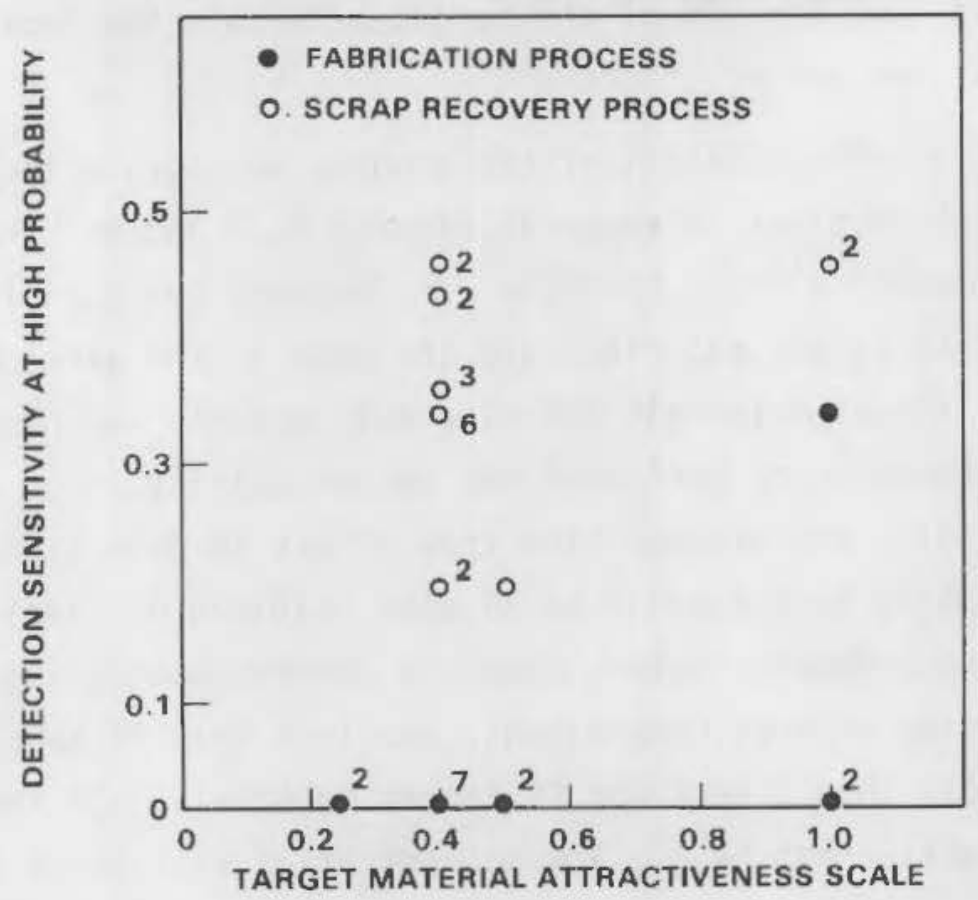

FIGURE 5. Detection Sensitivity for Diversion With Mass Substitution versus Target Material Attractiveness; HEU Plant. (Attractiveness values $<0.25$ omitted; sensitivity expressed as a fraction of the facility LEID)

further delay detection in many cases but with only small effects on sensitivity. Some falsification scenarios could prevent detection by this technique in certain process steps if record audits and internal controls were not thorough. In many target material locations the collusion of two or more plant personnel would be required to successfully falsify data without prompt detection.

For the high-enriched uranium fuels fabrication facility, 58 of 59 target materials are included in the process monitoring data. The target material not included is a low concentration recycle solution in the scrap recovery process. The average timeliness of the proposed system, based on process monitoring data for the case of a single loss without concealment, was less than 24 hours for 43 target materials and less than 1 week for 6 target materials. The detection sensitivity for the proposed system, where process 
data are available, is a factor of two better than current accounting for all target materials, and for $30 \%$ of the target materials the improvement is more than a factor of ten better.

The detection effectiveness of the process monitoring technique for the MOX fuel fabrication plant is shown in Figures 6,7 and 8 . The data are displayed in a manner similar to those for the previous facility. For this facility, 61 of 73 target materials are included in the process monitoring data; the other target materials are cleanout, wastes, and product materials where the measurements are performed for accountability. For all but 5 of the 73 target materials, the average time from a loss to detection by the current materials accounting system would be 30 days (maximum 60 days). The average timeliness of the proposed system, based on process monitoring data for the case of a diversion without concealment, was less than 24 hours for 37 target materials and less than 1 week for 24 target materials. Of the 12 remaining, 5 have low attractiveness (e.g., low concentration wastes), 5 are controlled as sealed items, and the other two are cleanout materials. The detection sensitivity for the proposed system (i.e., the grams of SSNM loss that would be detected with high probability) is a factor of at least two better than the current accounting system for all applicable target materials, and for $60 \%$ of the target materials the improvement is more than a factor of ten better.

The ability to identify the process location or target material from which a loss or diversion occurred when an anomaly is observed is referred to as localization capability. An example of typical localization capabilities is shown in Table 2 using data for the MOX plant. The results for the HEU plant are similar. Localization of diversion alarms is shown by target material in Part a and by unit operation in Part b. In the second and third columns the number of diversion monitoring measurement points are given for which an alarm could be localized to only one (1), two (2), three (3), etc., target materials and unit operations, as given in the 1st column. For example, in the no substitution case, there are seven monitoring points for which an alarm would be uniquely associated with a single target material and nine for which an alarm would be associated with just two target materials. Note that the mass substitution scenario results in poorer localization than 


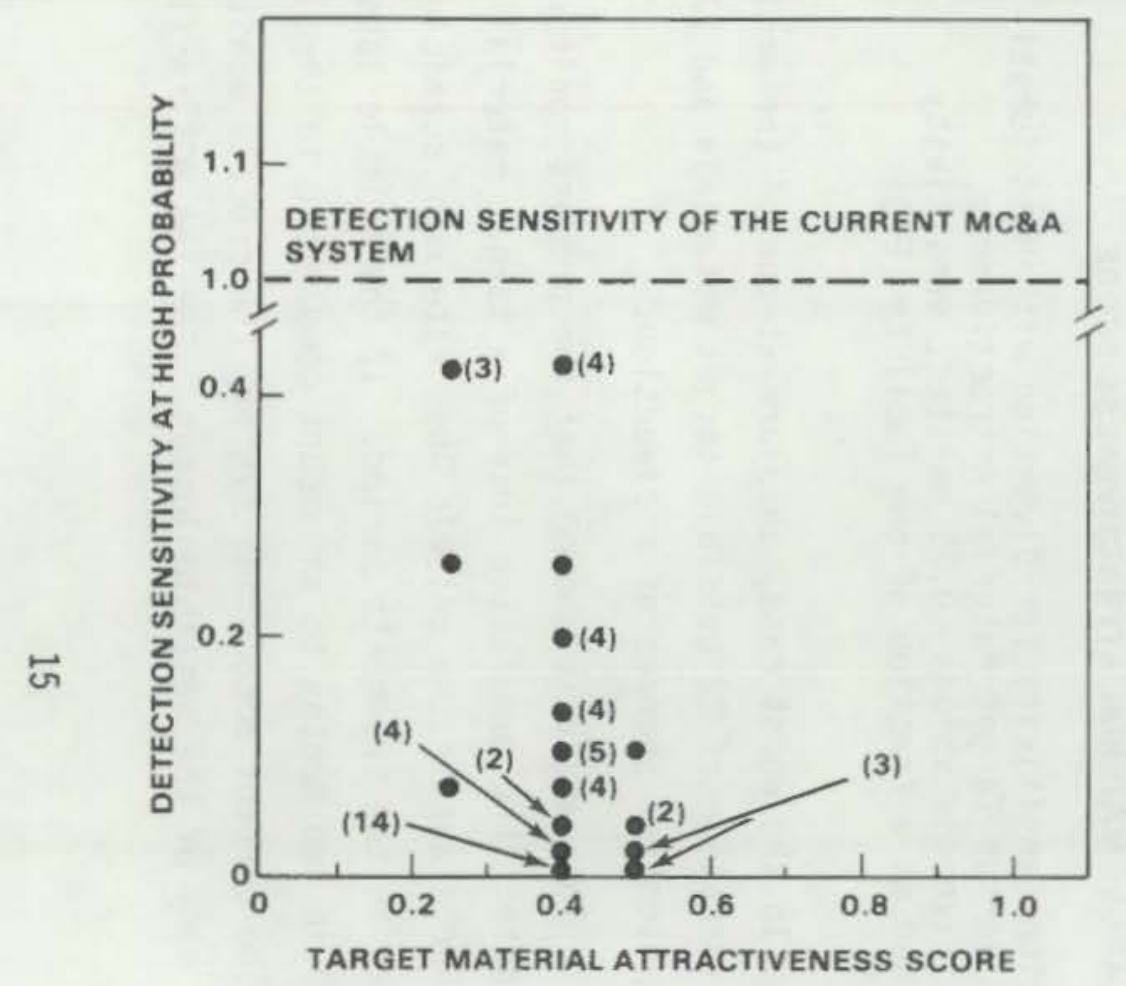

FIGURE 6. Detection Sensitivity versus Target Material Attractiveness; MOX Plant. (Attractiveness values $<0.25$ omitted; sensitivity expressed as a fraction of the facility LEID)

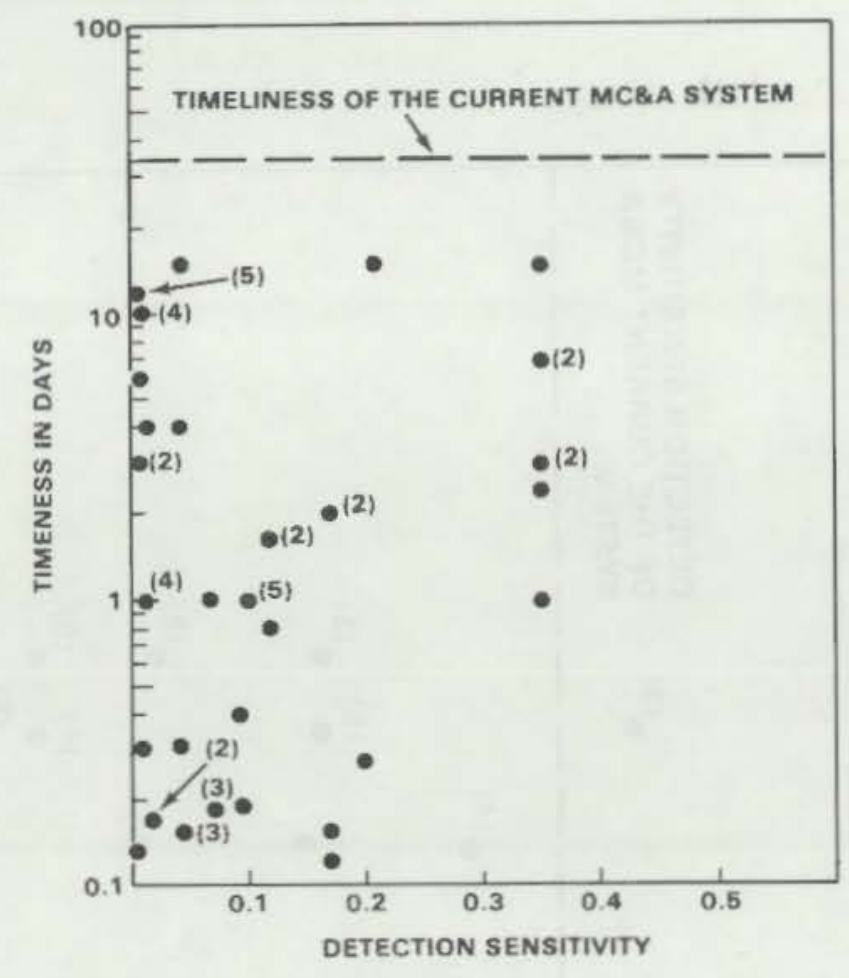

FIGURE 7. Detection Sensitivity versus Timeliness: MoX Plant. (Sensitivity expressed as a fraction of the facility LEID) 


\section{DIVERSION WITH MASS SUBSTITUTION}

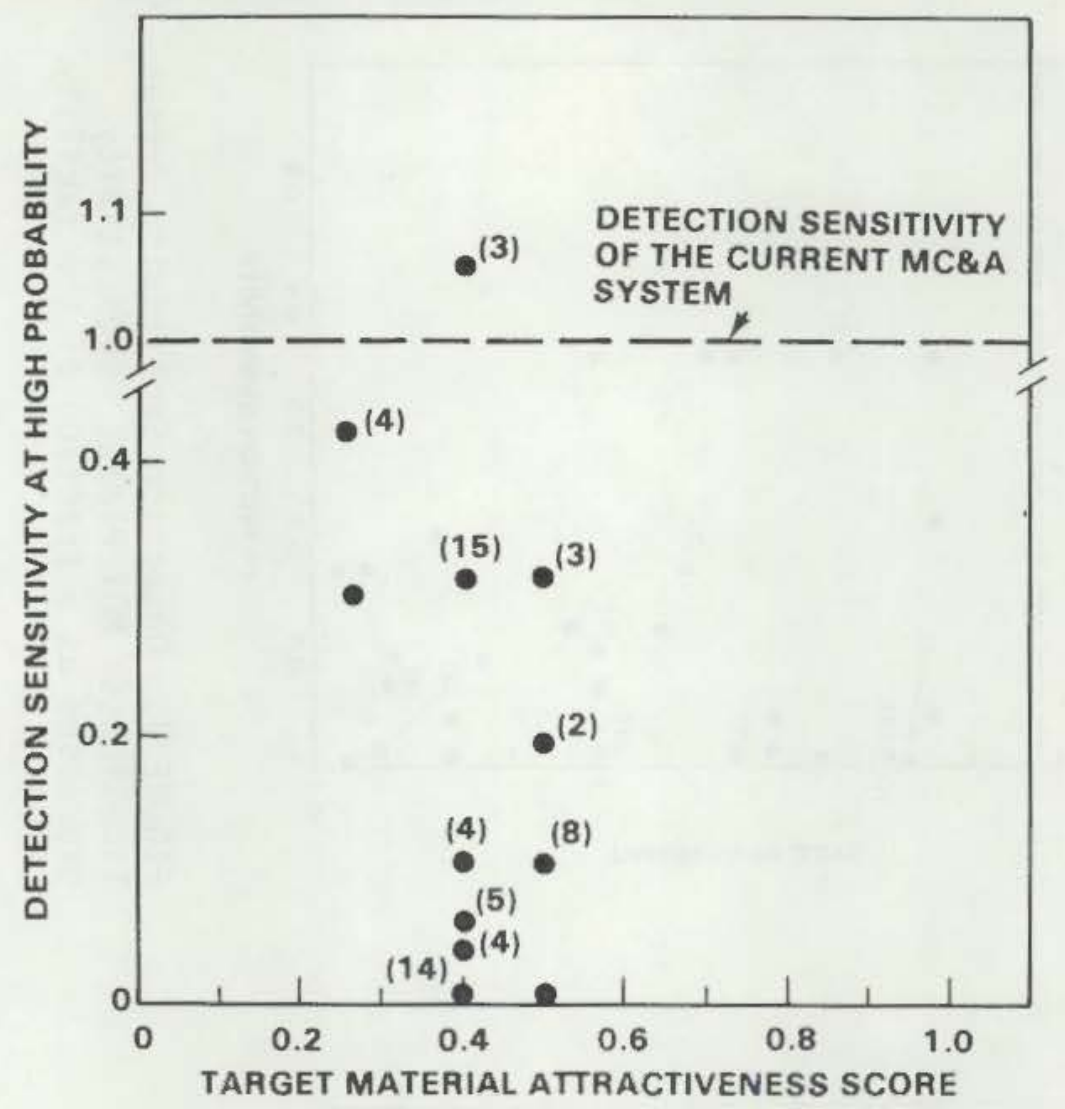

FIGURE 8. Detection Sensitivity for Diversion with Mass Substitution versus Target Material Attractiveness. (Attractiveness values $<0.25$ omitted; sensitivity expressed as a fraction of the facility LEID)

the no-substitution case. In the worst case, an alarm at one of the monitoring points would require consideration of 22 possible target materials and 17 possible unit operations as potential sources of a diversion.

The results of trickle loss analysis showed that the process monitoring technique would probably detect the cumulative loss of a target material in two months or less in either plant if the trickle loss rate were sufficiently high to accumulate to $5 \mathrm{Fkg}$ in the two-month period. If the trickle loss were at a rate that accumulated in two months to an amount comparable to the detection sensitivity of the current accounting system, the process monitoring system would still detect many of the possible losses. For the MOX facility, 
46 target materials would show no difference in detection effectiveness between single and trickle losses, 11 would require analys is of data over several 1ots, and 9 would not have enough sensitivity to detect the trickle loss in 8 weeks. For the HEU facility, 11 target materials wou?d show no difference in detection effectiveness between a trickle and a single loss, 21 target materials would have to be monitored over several lots to have the capability of trickle loss detection, and 26 would not be detected as a trickle loss in 8 weeks. Even though the process monitoring technique daes not detect all losses, it should be noted that in the event of an excessive inventory difference (ID), the investigation could be concentrated on those detection units where sensitivitles are insufficient to detect the trickle loss within the material balance period.

Because these statements are based on low false alarm rates and high probability of detection, there will also be evidence that can be used to test specific hypotheses about the source of the ID, only at some lower probabilty than that used in this systen. A7so, the system evaluation did not take cred it for limitations on frequency of access to the process, presence of other personnel that might deter the diversion, and the benefits of the physical security syster. 
TABLE 2. Localization Effectiveness of the Process Monitoring Technique

Number of Target

Materials or Units

Monitored at the

Number of Diversion

Diversion Monitor-

ing Point

Monitoring Measurement Points

Without Sub- with Mass Sub-

stitution stitution

$\begin{array}{lll}\text { a. Localization by Target Material } & \\ 1 & 7 & 2 \\ 2 & 9 & 3 \\ 3 & 4 & 2 \\ 4 & 3 & 1 \\ 5 & 2 & 1 \\ 6 & 2 & \\ 10 & 1 & \\ 13 & & 1 \\ 17 & & 1 \\ 22 & & 1\end{array}$

b. Localization by Unit Operation

1

10

3

2

8

3

3

5

3

4

1

5

1

6

2

9

1

13

14

17

(1)

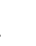

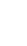

(1)




\subsection{INVESTIGATION OF ALARMS}

An important cost element in the inclusion of the process monitoring technique into SNM accountability would be the investigation of alarms. Alarns due to innocent causes only may result from:

- A random deviation of the process sufficient to cause a loss indicator value that exceeds the control limit. The frequency is predictable from the process variance, and raising the control limit will reduce the frequency of false alarms.

- A random deviation of a measurement result sufficient to cause a loss indicator value that exceeds the control limit. The frequency is predictable from the measurement yariance and raising the control limit will reduce the frequency.

- A nonrandom process deviation for which a specific cause usually can be found. The alarm rray be anticipated by close observation of the process operation.

- A nonrandon measurement deviation caused by an out-of-control situation. A good measurement control program can maintatn the frequency of such events to a negligible level.

- Human errors in perfoming measurements. The opportunities for a false assay result due to a human error are numerous but the frem quency of weighing errors should be quite small.

- Human errors in recording and copying measurement data and information,

Human errors in performing measurements and recording data are expected to be the major source of alarms. Some of these alarms 111 be resolved quick ly by review of recorded data and calculations, while others will require checks of labels, criticality safety sheets, or remeasurements of items still in the process line. Because of the timeliness af process monitoring, it is expected that this type of alarn will usually not be difficult to resolve. Alarms due to unusual process variability may be much more difficult to 
evaluate. Additional measurements of process material, holdup measurements, assay of scrap and recycle material, or improved measurements may resolve these alarms, but because of the localization of process data, these are not expected to affect the whole process. Resolution will also be useful to production and quality control and should coincide with normal operating practices. 


\subsection{CONCLUSIONS}

Loss monitoring effectiveness of the process monttoring technique for the target materials in bulk material processing is usually uniquely affected by the spexific processing operation. Generalizations of the sensitivity, timeliness and localization are not feasible, except that for the vast majorty of the target materials in these two facilities, loss detection effectiveness is better than the capablitities of the current sSNM accounting systems. Loss detection time periods are usually few days in contrast to many weeks, and target material sensitivities are usually a smali fraction of the typical facility IEID, largely as a consequence of the short time spans involved between measurements. In addition, loss alarms would generally localize the trouble point to a small part of the process area. Because of the inability of the current \$SW accounting system to distingutsh between block and trickle Josses within the two-month period, the process monitowing technique is gener ally more senstive to early detection of trick le losses.

It was observed that the process monitoring data are current ly monitored by the staff in these two licensed facllities. If a sufficient loss accurred at any of the monitored points in the process, an anonaly in the process data would be observed and an investigation would undoubtedly follow. However, for malization of the system and involventent of safeguards personnel would probably improve loss detection timeliness and the overail effectiveness for safeguards. 



\section{REFERENCES}

1. Miles, 3. C. J. E. Glancy and S. E. Donelson, "use of Process Monttoring Data for Enhancement of Nuc lear Material Control and Accounting.

3. Nuclear Mater. Manage. Proceedings I\$sue, Vo1. VIII, pp. 264-271. Institute of Wuc Tear Materials Management, 11702 Bowman Grean Dr., Reston, Virginia, 1979.

2. Miles, J. C., 3. E. Glancy and S. E. Donelson, Use of Process Monitoring Data for Enhancement of Nuclear Material control and Accounting. NuREG CR-1013 (MLM-2643). National Technical Inforration Service, Springfield, Virginta, 1979.

3. Report of the Material Control and Material Accounting Task Force, NUREG0450, Vol. 2, Nuc lear Regulatory Comission. Washington, U.C. 1978.

4. Wincek, M. A., K. B. Stewart and G. F. Plepel, Statistical Methods for Evaluating Sequential Material Balance Data, NURECTCR-0683, PNL-2920, National Technical Information Service, Springfield, Virginia, 1979. 


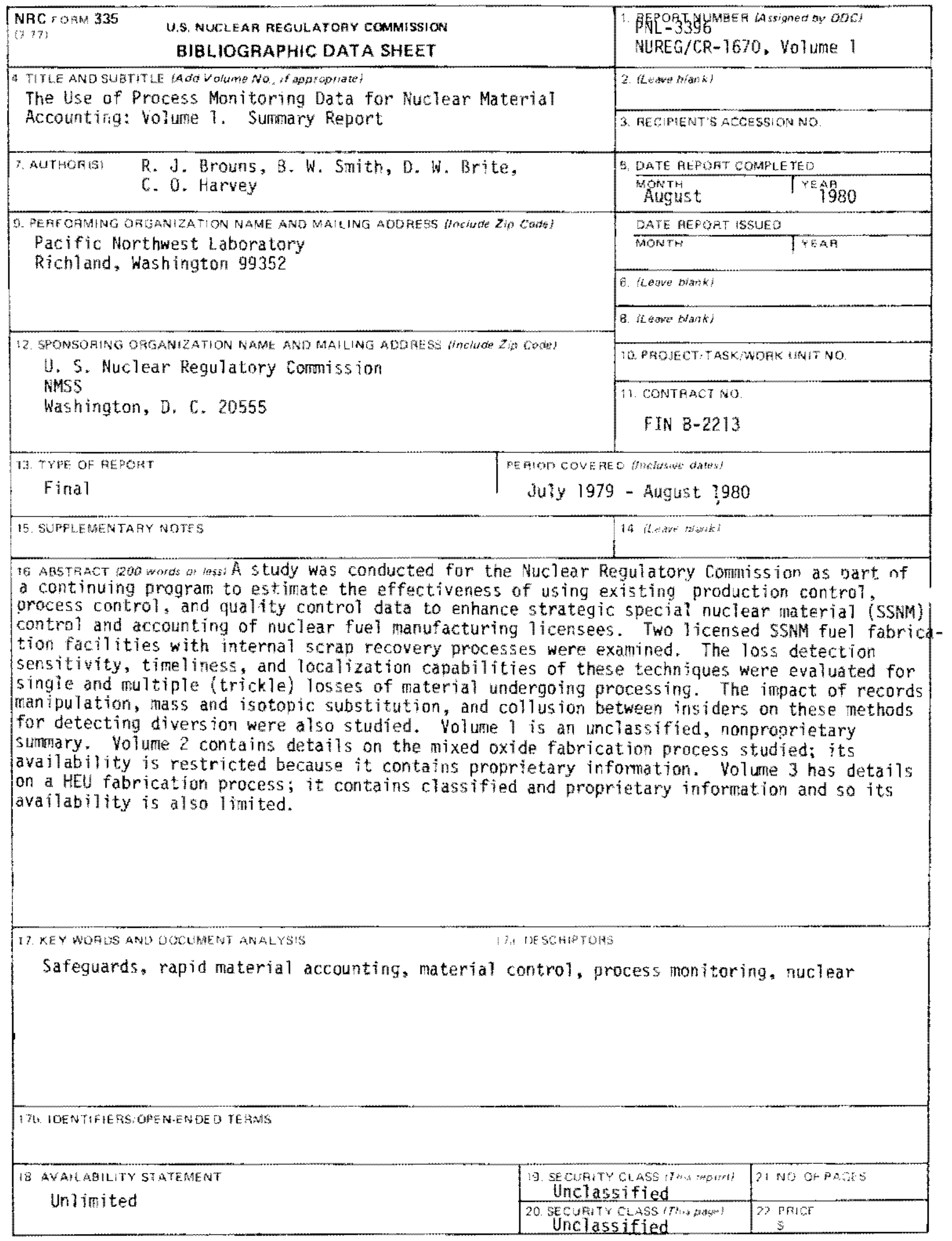


